\title{
Experimental investigation of the failure of steel AISI 316 by the methods of structural analyses
}

\author{
A. A. Abu Ghazal ${ }^{\dagger}$, P. S. Dzhumaev, A. V. Osintsev, V.I. Polsky, V. I. Surin \\ †gazal.ayman@yandex.ru
}

National Research Nuclear University MEPhI, 31 Kashirskoe shosse, Moscow, 115409, Russia

The failure of reactor steel AISI 316 under tension was investigated by structural analysis and scanning contact potentiometry (SCP). In real time surface potentiograms were plotted by the change of which the growth of crack nucleus was tracked from its initiation till the stage of cup fracture formation. The nucleus of the microscopic crack on the potentiogram was first detected at the end of the next to the last cycle of testing at a load of $525 \mathrm{MPa}$ in the yield region and then was persistently reproduced on potentiograms in subsequent tests up to the failure. The most noticeable changes in the parameters of dynamic waviness and roughness occurred at the moments of sharp crack growth. Using the results of the SCP method, three main stages of crack development were identified. In the first one, under loads corresponding to the conditional yield point, a nucleus was formed in the region of the maximum tangential stresses. This region of localization arises as a result of macroscopic loss of stability due to the significant mechanical energy accumulation by the system, which leads to an increase in the magnitudes of the plastic strain fluctuations. The second stage, the one of a progressive growth of the crack nucleus, is the longest in time and lasts from the moment of detection of the nucleus to the sample failure. The amplitude of the electrical potentials in the central part of the sample increased with the rise in intensity of the applied load which is associated with an increase in the inhomogeneity of the internal stress field around the nucleus, as well as the accelerating creep process and the growth of plastic strain in this region. At the pre-failure stage in the hardened surface layer, a macro-groove appears in the form of a standing deformation wave along the fracture line. Under the microscope, shear strain bands on the sample surface are also visible.

Keywords: testing of materials for failure, methods of structural analysis, scanning contact potentiometry, potentiogram, microcrack nucleus.

УДК: 621.039.53: 620.179.118 (075)

\section{Экспериментальное исследование процесса разрушения стали ЭИ847 методами структурного анализа}

\author{
Абу Газал А. А. ${ }^{\dagger}$ Джумаев П. С., Осинцев А. В., Польский В. И., Сурин В.И. \\ †gazal.ayman@yandex.ru
}

Национальный исследовательский ядерный университет «МИФИ», Каширское ш., 31, Москва, 115409, Россия

Методами структурного анализа и сканирующей контактной потенциометрии (СКП) исследовано разрушение стали ЭИ847 при растяжении. Построены поверхностные потенциограммы в режиме реального времени, по изменению которых отслеживали рост зародыша трещины от момента ее появления до стадии формирования чашечного излома. Зародыш микроскопической трещины на потенциограмме впервые был обнаружен в конце предпоследнего цикла испытаний при нагрузке 525 МПа в области предела текучести и затем устойчиво воспроизводился на потенциограммах при последующих испытаниях вплоть до момента разрушения. Наиболее заметные изменения параметров динамической волнистости и шероховатости происходили в моменты резкого роста трещины. С применением результатов СКП идентифицированы три основные стадии развития трещины. На первой, при нагрузках, соответствующих условному пределу текучести, образовывался зародыш в области действия максимальных касательных напряжений. Эта область локализации возникает как результат макроскопической потери устойчивости в результате накапливания системой механической энергии, приводящей к росту масштабов флуктуаций пластической дефор- 
мации. Вторая стадия, стадия прогрессирующего роста зародышевой трещины, была наиболее продолжительная по времени и длилась с момента обнаружения зародыша до разрушения образца. Амплитуда электрических потенциалов в центральной части образца росла с увеличением интенсивности прикладываемой нагрузки, что связано с усилением неоднородности поля внутренних напряжений вокруг зародыша и ускоряющегося процесса ползучести и роста пластической деформации в этой области. На стадии предразрушения в упрочненном поверхностном слое образуется макрогофр в виде стоячей деформационной волны вдоль линии излома. Под микроскопом видны также полосы сдвиговой деформации на поверхности образца.

Ключевые слова: испытания материалов на разрушение, методы структурного анализа, сканирующая контактная потенциометрия, потенциограмма, зародышевая микротрещина.

\section{1. Введение}

Опыт эксплуатации коррозионностойких сталей в реакторных установках показывает, что воздействие напряжений от давления и температуры рабочей среды в течение длительного времени приводят к возникновению и развитию разного рода повреждений. Холоднодеформированные тонкостенные трубы из жаропрочной коррозионностойкой аустенитной стали 06Х16Н15М3Б (ЭИ847; ТУ 14-159-293-2005) применяются в качестве оболочки тепловыделяющего элемента. Эта сталь также рассматривается как кандидат для использования в конструкциях поглощающего элемента, при температурах $900-1200^{\circ} \mathrm{C}$, с комбинированным поглотителем $\mathrm{B}_{4} \mathrm{C}-\mathrm{Hf}$ для регулирующих органов реактора ВВЭР-1000 [1]. Высокий интерес к данной стали подтверждается также недавно опубликованными результатами [2 -4].

Поэтому исследование процесса разрушения стали ЭИ8437 является актуальным как для более глубокого понимания и выявления особенностей разрушения, которые могут влиять на безопасную эксплуатацию изготовляемых изделий, так и для совершенствования методов неразрушающего контроля, способных на ранней стадии выявить потенциально опасные структурные изменения в стали.

В последнем случае наиболее перспективным, на наш взгляд, является метод сканирующей контактной потенциометрии (СКП), показавший высокую эффективность при решении ряда прикладных задач [5-7].

Цель данной работы - исследование разрушения стали ЭИ847 методами электронной микроскопии и СКП для изучения формирования и развития областей мезо- и макропластической деформации, в которых происходит зарождение и развитие трещины.

\section{2. Методы исследования}

\section{1.Сканирующая контактная потенциометрия}

Потенциометрические измерения выполнены на программно-аппаратном комплексе «ElphysLAB-ИДС» мобильной информационно-диагностической системы, размещенной на ноутбуке Asus X554L [8]. Для проведения измерений в режиме ручного детектирования был разработан программируемый амплитудный дискриминатор (ПАД) измерительных сигналов с регулируемой шкалой амплитудной дискриминации в диапазоне 40 дБ. Назначение дискриминатора заключается в отсечке значений амплитуды сигнала, расположенных выше установленного порога, что позволяет исследовать распределение электрического потенциала на разных структурных уровнях сигнала (СУС).

Программно-аппаратный комплекс мобильной информационно-диагностической системы управляется OS Windows. Частота дискретизации измерений в данном представлении составляла 1 Гц, но при необходимости ее можно увеличить на 1-2 порядка $[9,10]$.

Плоские образцы из стали ЭИ847 размером $170 \times 50 \times 2$ мм были изготовлены фрезерованием из листового проката с последующей полировкой рабочей поверхности до шероховатости $R_{a}$ не хуже 0.3 мкм. Для измерения разности электрических потенциалов применяли датчики с электрофизическими преобразователями из меди М-2 и низкоуглеродистой стали Ст3. Механическое перемещение датчика по поверхности образца осуществляли по восьми измерительным дорожкам, четыре из которых принадлежали левой части образца (относительно продольной оси симметрии) и четыре - правой. Длина дорожки составляла около 90 мм, а расстояние между дорожками около 3 мм. При средней скорости сканирования 5 мм/с, время одного сета измерений изменялось в пределах двухминутного интервала. Распределение потенциалов на поверхности исследовалось относительно потенциала «массы» разрывной машины.

Испытания на растяжение проводили на электромеханической разрывной машине INSTRON-5982. Нагрузку повышали ступенчато, при пересчете на напряжение на 30 - 50 МПа после каждого текущего режима испытаний. Цикл с заданными значениями нагрузки завершали полной разгрузкой образца и фиксировали изменение его формы, а также измеряли шероховатость на рабочей поверхности. В течение одной недели после испытаний образец выдерживали в разгруженном состоянии при нормальных условиях, после чего испытания возобновлялись, начиная, как правило, с более высокого уровня нагрузки. В процессе эксперимента на каждом режиме измеряли температуру поверхности образца термопарой, показания которой в пределах погрешности измерений соответствовали комнатной температуре. Всего, до разрушения образца, было проведено пять циклов испытаний в интервале напряжений от 12 до 680 МПа.

\section{2. Оптическая и электронная микроскопия}

Поверхность разрушения образца исследовалась методами оптической и электронной микроскопии. Резка торцов для фрактографических исследований в растро- 
вом электронном микроскопе производилась на прецизионном отрезном станке МЕСАТОМЕ Т180.

Шлифы для исследований готовились на полуавтоматическом шлифовально-полировальном станке ПОЛИЛАБ П12 с использованием абразивов и полировальных сукон фирм Lamplan и Akasel различной зернистости. Контроль качества поверхности образца в процессе шлифовки осуществлялся в оптическом металлографическом микроскопе ММР-4. Итоговая шероховатость соответствовала двенадцатому классу чистоты поверхности с параметром $R_{a}$, равном 0.04 мкм.

Для исследования поверхности разрушения использовали также оптический микроскоп МБС-1 и цифровой оптический микроскоп MOTIC SMZ-143.

\section{3. Профилометрия поверхности}

Распределение волнистости и шероховатости на рабочей поверхности образца определяли с помощью универсального цифрового измерителя шероховатости поверхности фирмы VOGEL. Среднеарифметическое отклонение профиля поверхности измеряли вдоль восьми измерительных дорожек после каждого цикла испытаний на базе 0.25 мм (ГОСТ 2789-73).

\section{4. Измерение микротвердости}

Микротвердость измеряли на базе 1 мм, методом Виккерса на приборе HVS-1000 с автоматической подачей индентора при нагрузке, равной $1 \mathrm{H}$. Время выдержки под нагрузкой составляло около двадцати секунд. Относительная погрешность измерения была не выше 0.1.

Измерения микротвердости проводились на трех участках поверхности образца, причем на каждом из них производилось не менее тридцати измерений. Значения изменялись в пределах от трех до девяти тысяч МПа. Первый участок принадлежал продольной оси симметрии образца и располагался на расстоянии 40 мм от линии излома, второй - на расстоянии 10 мм от линии излома, и третий участок - в сечении излома. Соответствующие средние значения микротвердости равны 3934, 6642 и 7136 МПа.

\section{3. Результаты экспериментального исследования}

Поверхность излома представляет собой косой срез в сечении наибольшего утоньшения, с характерным зубом на одной половине образца и соответсвующей впадиной на другой половине в центральной его части. Размер зуба вдоль линии излома составляет около двух миллиметров (Рис. 1), боковые поверхности параллельны между собой и перпендикулярны нижней плоскости зуба.

Использование оптической и электронной микроскопии позволило полностью восстановить картину разрушения образца. Фрактограмма поверхности излома после механических испытаний представляет собой классическое вязкое разрушение по всей поверхности излома. Множественные ямки на поверхности свидетельствуют об образовании, росте и слиянии микропу- стот. Разрушению предшествовала значительная пластическая деформация 13\%, протекающая по всему объему образца и наиболее интенсивно проявившаяся в области сформировавшейся шейки. Вязкий характер разрушения подтверждается наличием развитой сетки, так называемых вязких перевязок, характеризующих данный тип разрушения, который на микроскопическом уровне обусловлен существенным упрочнением матрицы материала в результате наклепа при переменном нагружении-разгружении.

В подобных случаях, разрушение начинается с образования микронадрывов и слияния микропустот, которые с увеличением нагрузки активно коалесцируют. Трещины при вязком разрушении в сталях часто образуются на границе с неметаллическими включениями и имеют вид округлых полостей.

На основе результатов СКП идентифицированы три основные стадии развития трещины. На первой, при нагрузках, соответствующих условному пределу текучести, образовывался зародыш в области действия максимальных касательных напряжений. Эта область локализации возникает как результат макроскопической потери устойчивости в результате поступления в систему значительной механической энергии, приводящей к росту масштабов флуктуаций пластической деформации [11-13].

Вторая стадия - прогрессирующий рост зародышевой трещины, была наиболее продолжительная по времени и длилась с момента обнаружения зародыша до разрушения образца. Амплитуда электрических потенциалов в центральной части образца росла с увеличением интенсивности прикладываемой нагрузки и связана с усилением неоднородности поля внутренних напряжений вокруг зародыша, а также ускоряющегося во времени процесса ползучести и роста пластической деформации в этой области. Так при нагрузке $525 \mathrm{MПа}$ максимальное значение амплитуды диагностического сигнала было зафиксировано на уровне 2-х милливольт, при 591 МПа около 4-х милливольт, а при 650 МПа уже около шести милливольт.

На третьей стадии, после завершения формирования трещины и локализации течения в виде образовавшейся шейки, произошло разрушение, которое сопровождалось широким диапазоном амплитуд электрических потенциалов, что свидетельствует о присутствии как динамической шероховатости, так и волнистости с относительно большими длинами поверхностных волн. С помощью электронной микроскопии установлено среднее соотношение длины поверхностной волны $(\lambda$ к ее высоте $(h)$ в непосредственной близости к линии излома, равное $\lambda / h \sim$ нескольким десяткам. Обнаружены примыкающие к магистральной трещине более мелкие ответвления микротрещин, ориентированные под разными углами к линии излома.

На стадии предразрушения в упрочненном поверхностном слое образуется макрогофр в виде стоячей деформационной волны вдоль линии излома (Рис. 1b). Эта область характеризуется более высокими значениями микротвердости. Рельеф излома заметно отличен от рельефа поверхности образца, имеет более крупную зерновую структуру и образования в виде узких впадин и микроуглублений. 

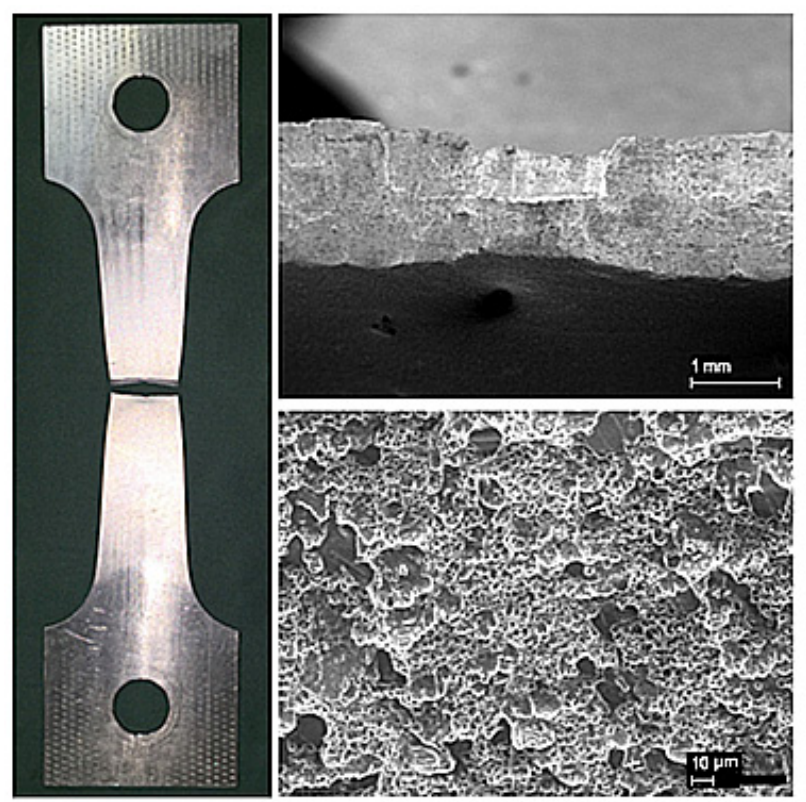
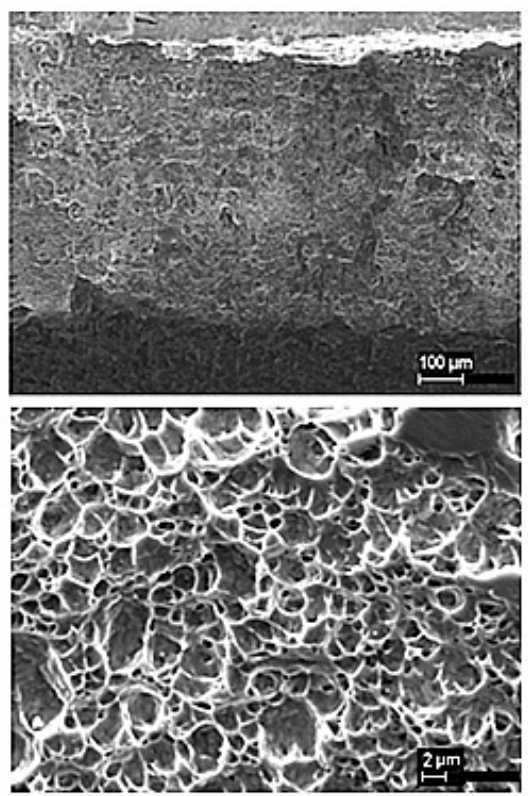

a

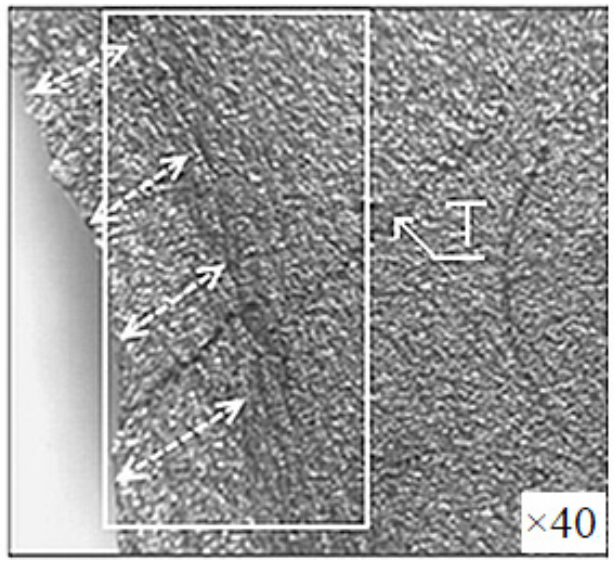

b

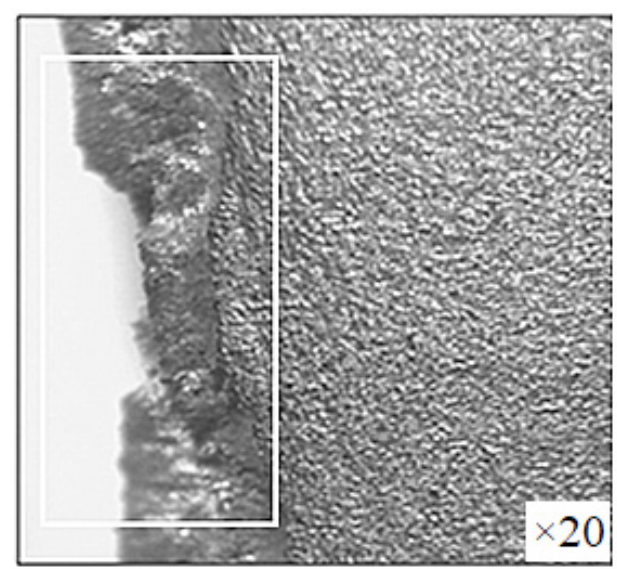

c

Рис. 1. Образец после испытаний (слева) и край излома в области образовавшегося зуба при разных увеличениях (а); фрагмент макрогофра у линии излома, выделенный прямоугольником и обозначенный двусторонними стрелками (b) и складки в области впадины зуба (c). На Рис. (b) показана также одна из ответвляющихся трещин длиной около 3 мм (обозначена буквой Т).

Fig. 1. The specimen after the test (left) and the fracture edge in the area of the formed tooth at different magnifications (a); a fragment of the macro-groove at the fracture line, highlighted by a rectangle and indicated by double-headed arrows (b) and folds in the area of the tooth cavity (c). Figure (b) also shows one of the branching cracks about $3 \mathrm{~mm}$ long (indicated by the letter T).

Под микроскопом также видны полосы сдвиговой деформации на поверхности образца (стрелки на Рис. 2b), с которыми связан неоднородный матовый цвет поверхности. Начало полос и наиболее насыщенный матовый цвет располагаются в области образовавшейся шейки. Полосы наблюдаются на обеих половинках образца, ближе к местам закрепления образца в захватах машины матовый градиент ослабевает. Предполагаемая природа полос может быть связана с прохождением макрополосы Чернова-Людерса.

На основе анализа потенциограмм, которые подтверждаются фрактографическим исследованием и измерениями шероховатости, можно сделать вывод, что с возрастанием нагрузки фронт пластической деформации продвигался от центра образца к захватам со скоростью нескольких сантиметров в час, при этом с изменением рельефа изменялся и цвет поверхности. Наиболее заметные изменения параметров динамической волнистости и шероховатости происходили в моменты резкого роста трещины. Следует отметить зрительную схожесть картины шероховатости с построенной потенциограммой в момент разрушения, приведенной на Рис. $2 \mathrm{~d}$ : уменьшение значений шероховатости, как и потенциала на поверхности, происходит от центра к периферии. Значение шероховатости в области разрушения возросло более чем в четыре раза по сравнению с начальным.

Микротвердость, измеренная в зоне деформационного упрочнения после разрушения образца (зона зуба), возросла почти в два раза по сравнению с начальным значением.

Амплитуду диагностического сигнала анализировали на разных СУС, СУС $=|\lg \Delta \varphi|, \Delta \varphi-$ измеренная разность потенциалов $[14,15]$. Под нагрузкой в образце дефекты 


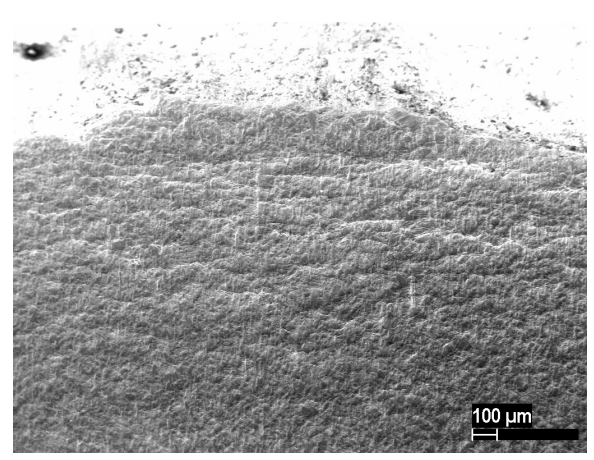

a

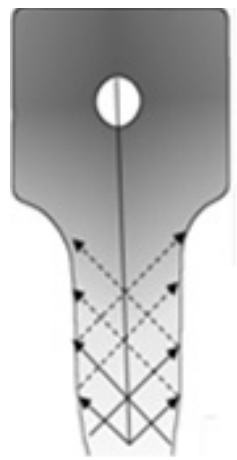

b

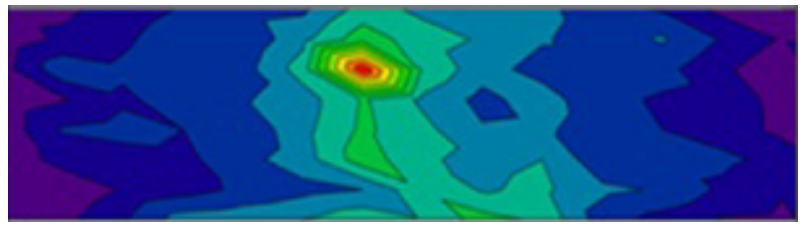

c

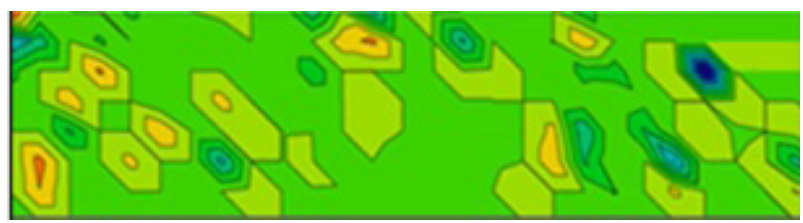

d

\begin{tabular}{|c|c|c|c|c|c|c|c|c|c|c|l|}
\hline Цвет/Color & & & & & & & & & & & \\
\hline$R_{a}(\mu \mathrm{m})$ & 1.3 & 1.2 & 1.1 & 1.0 & 0.9 & 0.8 & 0.7 & 0.6 & 0.5 & 0.4 & 0.3 \\
\hline$\Delta \varphi(\mathrm{mV})$ & 3.6 & 2.6 & 1.6 & 0.6 & 0.5 & -0.4 & -1.4 & -2.4 & -3.4 & -4.4 & -6.4 \\
\hline
\end{tabular}

e

Pис. 2. (Color online) Волнистость в области образовавшегося зуба (а) и направление распространения матовых полос на поверхности после разрушения образца (b), а также шероховатость поверхности образца после его разрушения (c) и потенциограмма поверхности в момент разрушения при нагрузке $630 \mathrm{MПа}(\mathrm{d})$. Шкала шероховатости $\left(R_{a}\right)$ и разности электрических потенциалов $(\Delta \varphi)$ на поверхности образца при его разрушении (е).

Fig. 2. (Color online) Waviness in the area of the formed tooth (a) and the direction of propagation of matte strips on the surface after the failure of the sample (b), as well as the surface roughness of the sample after its failure (c) and the surface potentiogram at the moment of failure at a load of $630 \mathrm{MPa}(\mathrm{d})$. Roughness scale $\left(R_{a}\right)$ and electric potential difference $(\Delta \varphi)$ on the surface of the sample during its failure $(\mathrm{e})$.

становятся активными, формируются области концентрации напряжений. Напряжения первого и второго рода (по критерию Давиденкова) наиболее существенно влияют на знак и амплитуду диагностического сигнала, при этом практически всегда экранируется составляющая сигнала, связанная с напряжениями третьего рода.

Зародыш микроскопической трещины на потенциограмме впервые был обнаружен в конце предпоследнего цикла испытаний при нагрузке 525 МПа в области предела текучести и затем устойчиво воспроизводился на потенциограммах при последующих испытаниях вплоть до момента разрушения. Размер области зародышевой микротрещины при напряжении 525 МПа в момент локации зародыша составляет от 100 до 200 мкм (Рис. 3). С увеличением нагрузки размеры зародыша увеличивались и при разрушении возросли примерно в три раза. Эквивалентная площадь зародыша вычислена по формуле $S_{\text {экв }}=R \cdot \lambda=2 \times 10^{3}$ мкм $^{2}$, где $R-$ радиус пятна контакта.

Как показали наблюдения и замеры формы и толщины образца зародыш образовался задолго до момента макролокализации и образования шейки. Очаг локализации разрушения геометрически совпал с местом появления зародыша на потенциограммах.

Зародыш имеет вид шестиугольника, вытянутого вдоль оси, составляющей угол 45 градусов с направлением прикладываемой нагрузки (Рис. 3c). В центре шестиугольника на уровнях дискриминации от $1 \cdot 10^{-5} \mathrm{~B}$ до $3.7 \cdot 10^{-4} \mathrm{~B}$ располагается область высоких положительных значений потенциала. Значения потенциала постепенно уменьшаются в направлении от центра к границам шестиугольника, а сам зародыш окружен чередующимися косыми полосами.

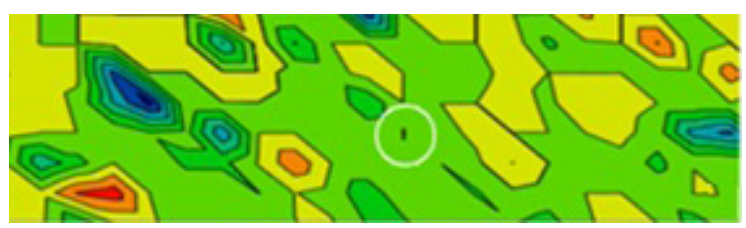

a

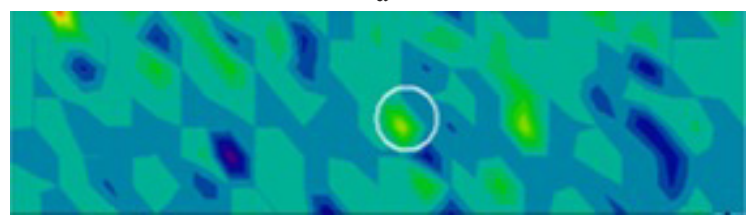

b

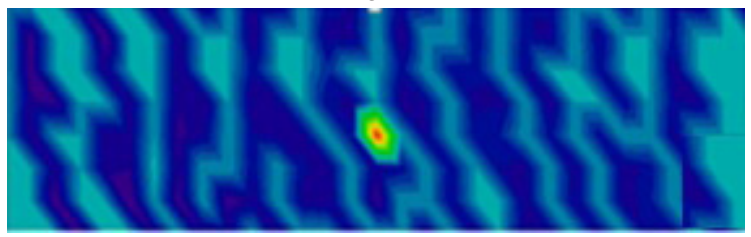

Pис. 3. (Color online) Потенциограммы момента локации зародыша микротрещины при напряжении 525 МПа (a) и $550 \mathrm{MПа} \mathrm{(b,} \mathrm{c)} \mathrm{для} \mathrm{СУС}=1.23$ (a,b) и $4.62 \leq \mathrm{CУC} \leq 4.854$ (c). Зародыш на двух верхних потенциограммах выделен белым кружком.

Fig. 3. (Color online) Potentiograms at the moment of the location of the microcrack nucleus at stresses of $525 \mathrm{MPa}$ (a) and $550 \mathrm{MPa}(\mathrm{b}, \mathrm{c})$ for SLS $=1.23(\mathrm{a}, \mathrm{b})$ and $4.62 \leq \mathrm{SLS} \leq 4.854$ (c). The nucleus on the two upper potentiograms is marked by a white circle.

По знаку потенциала полосы соответствуют областям с сжимающими поверхностными напряжениями, которые ориентированы на под тем же углом, что и ось шестиугольника, т. е. под 45 градусов относительно направления нагрузки. 


\section{4. Выводы}

Исследовано разрушение стали ЭИ847 при растяжении методами структурного анализа и СКП. Построены поверхностные потенциограммы в режиме реального времени, по изменению которых отслеживали рост зародыша трещины от момента ее появления до стадии формирования чашечного излома.

Установлена связь между параметрами диагностического сигнала и структурными изменениями материала. Следствием увеличения амплитуды сигнала в процессе локализации течения в виде образовавшейся шейки является причина роста числа пятен контакта, а также увеличение размеров уже существующих пятен контактов на поверхности взаимодействия «преобразовательобразец», при усилении волнистости и шероховатости в зоне очага разрушения. Шероховатость $R_{a}$ в области разрушения возросла более чем в четыре раза по сравнению с начальными значениями и в очаге разрушения соответствовала значению 1.3 мкм.

Оценка размеров области образования зародыша при напряжении 525 МПа составляет от 100 до 200 мкм и характеризует порог чувствительности обнаружения микроскопической трещины методом СКП. Глубина залегания трещины лежит в интервале от нескольких десятых до 2-х миллиметров, что соответствует начальной толщине пластины. С увеличением нагрузки размеры зародыша увеличивались и при разрушении возросли примерно в три раза. Оценка эквивалентной площади зародыша трещины соответствует значению $2 \times 10^{3}$ мкм $^{2}$.

\section{Литература/References}

1. V.S. Krasnorutskiy, N.N. Belash, A.M. Abdullayev, A.I. Zhukov, I.A. Petelguzov, N. Mikhailov, E.A. Slabospitskaya. Questions of atomic science and technology. 2, 88 (2007). (in Russian) [B.С. Красноруцкий, Н.Н. Белаш, А.М. Абдуллаев, А.И. Жуков, И.А. Петельгузов, Н.А. Михайлов, Е. А. Слабоспицкая. Вопросы атомной науки и техники. 2, 88 (2007).]

2. A.V. Shulga. Journal of Nuclear Materials. 434, 133 (2013). DOI: $10.1134 / \mathrm{S} 1063778817100088$

3. C. Schroer, O. Wedemeyer, J. Novotny, A. Skrypnik, J. Konys. Journal of Nuclear Materials. 418, 8 (2011).

4. H. B. Li, Z. H. Jiang, H. Feng, S. C. Zhang, L. Li, P. D. Han, R.D. K. Misra, J.Z. Li. Journal of Materials and Design. 84, 291 (2015).

5. V.I. Surin. Nuclear Engineering International. (2018). http://www.neimagazine.com/features/featurenewpotential-for-potentiometry-6146360/

6. V.I. Surin And N.A. Evstyukhin, V.I. Knyazev, S.N. Tarasov, K.L. Pisarenko. Technique of reactor experiment. Moscow, Energoatomizdat. (1987) p. $80-85$. (in Russian) [В. И. Сурин, Н. А. Евстюхин, В. И. Князев, С.Н. Тарасов, К. Л. Писаренко. Техника реакторного эксперимента. Москва, Энергоатомиздат. (1987) с. 80 - 85.]

7. V.I. Surin, N.A. Evstyukhin, V.I. Cheburkov J. Nucl. Mater. 218, 268 (1995).

8. V.I. Surin, Z.S. Volkova,R. A. Denisov, V.D. Motovilin., N.In. Raine. Global nuclear security. Moscow, National Research Nuclear University MEPhI. (2016), 4 (21), p. 51-62. (in Russian) [В.И. Сурин, 3.С. Волкова, Р. А. Денисов, В. Д. Мотовилин., Н. В. Рейн. Глобальная ядерная безопасность. Москва, НИЯУ МИФИ. (2016), 4 (21), c. 51-62.]

9. A. A. Abu Ghazal, G.D. Bokuchava, I.V. Papushkin, V.I. Surin, E. A. Shief. Theses of the 17th international scientific and practical conference. Moscow (2017), p. 66. (in Russian) [А.А. Абу Газал, Г.Д. Богучава, И. В. Папушкин, В.И. Сурин, Е. А. Шеф. Тезисы 17-й международной научно-практической конференции. Москва (2017), с. 66.]

10. A.A. Abu Ghazal, R.A. Denisov, A.V. Lisenkov, V.I. Surin. Modern problems of theory machines/SEC "MS". 4 (1), 184 (2016).

11. M.A. Shtremel. The strength of the alloys. Part II. Moscow, MISIS. (1997). (in Russian) [M. А. Штремель. Прочность сплавов. Часть II. Москва, МИСИС (1997).]

12. L. B. Zuev, S. A. Barannikova, S. Y. Breeders. Physics of metals and metallurgy. 87 (3), 77 (1999). (in Russian) [Л.Б. Зуев, С.А. Баранникова, С. Ю. Заводчиков. Физика металлов и металловедение. 87 (3), 77 (1999).]

13. V.E. Panin, V. S. Pleshanov, S. A. Burkova, S. A. Kobzeva. Materials science. 22 (1991). (in Russian) [B.Е. Панин, В.С. Плешанов, С.А. Буркова, С.А. Кобзева. Материаловедение. 22 (1991).]

14. V.I. Surin, Z.S. Volkova, A. A. Abu Ghazal, A. I. Elwahab, E.H. Alsmadi. Fundamental and applied research in the modern world: Materials of the XXI International scientific and practical conference. St. Petersburg (2018). p. 188 (in Russian) [В. И. Сурин, 3. С. Волкова, А.А. Абу Газал, А.И. Алвахеба, Э.Х. Альсмади. Фундаментальные и прикладные исследования в современном мире: Материалы XXI Международной научно-практической конференции. Санкт-Петерсбург (2018) c. 188]

15. A.A. Abu Ghazal, G.D. Bokuchava, I.V. Papushkin, V.I. Surin, E.A. Shef. The application of scanning contact potentiometry method and diffraction of thermal neutrons at physico-mechanical tests of materials: Proc. of the XIII International Youth Scientific and Practical Conference "FUTURE OF ATOMIC ENERGY AtomFuture 2017", KnE Life Sciences (2017) p. 91. DOI: $10.18502 /$ keg.v3i3.1611 